\title{
Fatty Acid Kinetic Responses to Exercise \\ Effects of Obesity, Body Fat Distribution, and Energy-restricted Diet
}

\author{
Jill A. Kanaley, ${ }^{*}$ Philip E. Cryer, ${ }^{\star}$ and Michael D. Jensen* \\ ${ }^{*}$ Endocrine Research Unit, Mayo Clinic, Rochester, Minnesota 55905; and ${ }^{\ddagger}$ Division of Endocrinology, Diabetes, and Metabolism, \\ Washington University School of Medicine, St. Louis, Missouri 63110
}

\begin{abstract}
Upper body obesity (UB Ob) is associated with a reduced net free fatty acid (FFA) response to epinephrine compared with nonobese (Non $\mathrm{Ob}$ ) and lower-body obese (LB Ob) women. Because catecholamines regulate some of the metabolic responses to exercise, we hypothesized that $\mathrm{UB} \mathrm{Ob}$ would have a reduced net FFA response to exercise. Plasma FFA rate of appearance (Ra) ([1-14 C]palmitate) and fatty acid oxidation (indirect calorimetry) were therefore measured during $2.5 \mathrm{~h}$ of stationary bicycle exercise $\left(45 \% \mathrm{VO}_{2}\right.$ peak $)$ in $13 \mathrm{UB} \mathrm{Ob}, 11$ LB Ob, and 8 Non Ob premenopausal women. $10 \mathrm{UB} O b$ and 8 LB Ob women were retested after an $\sim 8$-kg weight loss. Results: During exercise Non $\mathrm{Ob}$ and $\mathrm{LB} \mathrm{Ob}$ women had greater increments in FFA availability (51 \pm 7 and $53 \pm 8 \mathrm{mmol}$, respectively) than UB Ob women $(27 \pm 4 \mathrm{mmol}, P<0.05)$. Total exercise FFA availability and fatty acid oxidation were not different between Non $\mathrm{Ob}, \mathrm{LB} \mathrm{Ob}$, and $\mathrm{UB} \mathrm{Ob}$ women, however. Following weight loss $(\sim 8 \mathrm{~kg})$, the FFA response to exercise increased $(P<0.01)$ and remained greater $(P<0.05)$ in $\mathrm{LB}$ $\mathrm{Ob}$ than in $\mathrm{UB} \mathrm{Ob}$ women. In conclusion, the FFA response to exercise was reduced in $\mathrm{UB}$ Ob women before-and after weight loss, but no effects on fatty acid oxidation were apparent. ( $J$. Clin. Invest. 1993. 92:255-261.) Key words: free fatty acids • indirect calorimetry • obesity • weight loss • body composition
\end{abstract}

\section{Introduction}

Upper body obesity (UB Ob $)^{1}$ is associated with several abnormalities of free fatty acid (FFA) metabolism in moderately obese women, including increased basal FFA flux and a reduced net (incremental) lipolytic response to epinephrine (1). Adipose tissue lipolysis, virtually the only source of circulating FFA in the postabsorptive state, is largely controlled by insulin and catecholamines, both by changes in their concentrations (2) and by the sensitivity of adipocytes to their presence (3). Free fatty acid release increases during exercise, providing an important circulating fuel for muscle. Catecholamines are thought to play a critical role in assuring normal exercise FFA availability (4). If the lipolytic response to catecholamines dur-

Address reprint requests to Michael D. Jensen, M.D., Endocrine Research Unit, 5-164 West Joseph, Mayo Clinic, Rochester, MN 55905. 1993.

Received for publication 6 July 1992 and in revised form 3 February

1. Abbreviations used in this paper: LBM lean body mass; LB Ob, lower body obese; Non OB, nonobese; Ra, rate of appearance; UB Ob, upper body obese.

The Journal of Clinical Investigation, Inc.

Volume 92, July 1993, 255-261 ing exercise is subnormal in upper body obesity, loss of fat might be impaired and exercise capacity limited. The regulation of energy metabolism during exercise is especially relevant in obesity because exercise is an important component of successful weight-reduction programs (5).

The ability to maintain exercise is dependent upon the energy supply meeting the energy demands of working muscles, which oxidize both fat and carbohydrate (6-8). During prolonged exercise carbohydrate oxidation decreases while fatty acid oxidation increases (7). Both intramuscular triglycerides and circulating FFA are potential sources of fatty acids $(8,9)$. In lean men, FFA availability exceeds fatty acid oxidative needs during prolonged, low intensity exercise (10). Women, however, have greater proportionate lipid oxidation during exercise than men (11), and it is unknown whether FFA availability is adequate to meet the energy needs of working muscle in lean or obese women. An inadequate lipolytic response to exercise in upper body obese women could result in accelerated depletion of intramuscular glycogen and triglycerides and therefore limit exercise endurance capacity. This, in turn, could discourage participation in regular exercise.

Few investigations (12-14) have examined the effects of weight loss on the FFA response to exercise. Some studies have reported that exercise-induced increments in plasma FFA concentrations are less during weight loss than before caloric restriction (12), whereas others have observed the opposite phenomenon $(13,14)$. The reasons for these discrepant results may be related to the exercise protocols employed, degree of caloric restriction, or heterogeneous study subjects. In addition, only plasma FFA concentrations were measured (1214), and changes in FFA clearance with exercise (7) and obesity (1) limit the interpretation of such data. Because plasma FFA concentrations may not reflect release rates during exercise, the possibility remains that weight loss could modify the adipose tissue response to exercise such that FFA release is reduced.

The purpose of this study was threefold: $(a)$ to determine if body fat distribution influences the incremental lipolytic response to prolonged, submaximal exercise in moderately obese women compared with nonobese women; $(b)$ to examine whether FFA availability in these three groups of women equals or exceeds fatty acid oxidation (as measured by indirect calorimetry) during exercise and recovery; and $(b)$ to determine whether 16 wk of a modestly energy-restricted diet reduces FFA release during exercise and whether this response is influenced by body fat distribution. Knowing that upper-body obese women have a reduced incremental FFA response to an epinephrine infusion, it was hypothesized that upper body obese women would have a subnormal FFA response to exercise. We also hypothesized that following weight-loss exercise, FFA availability would decrease only in upper body obese women. 


\section{Methods}

Subjects. Informed, written consent was obtained from 24, healthy, moderately obese, premenopausal women and 8 nonobese (Non Ob) women. 13 obese women had waist-to-hip ratios $>0.85$ (UB Ob) and 11 had waist-to-hip ratios $<0.76$ ( $\mathrm{LB} \mathrm{Ob}$ ). The subjects were taking no medications, had maintained a stable weight for at least 2 mo before the initial studies, and had consumed a diet containing more than $200 \mathrm{~g}$ of carbohydrate daily for at least $2 \mathrm{wk}$ before the studies. All studies were performed in the follicular phase of each woman's cycle.

\section{Experimental design}

Anthropometric measurements, body composition assessments, and peak aerobic capacity were measured before the first study day. Plasma FFA kinetics were studied during a prolonged, low intensity $\left(45 \% \mathrm{VO}_{2}\right.$ max) bicycle-exercise test performed when the subjects were in the overnight postabsorptive state. Following the first FFA kinetic study, the obese women began a 16-wk, moderate caloric-restriction diet. At the end of $4 \mathrm{mo}$, while continuing to consume the same diet, subjects were retested on the pretest measurements and repeated the FFA kinetics study.

Materials and assays. $\left[1-{ }^{14} \mathrm{C}\right]$ Palmitate (Amersham Corp., Arlington Heights, IL) was prepared for intravenous infusions as previously described (15). Plasma palmitate, FFA concentrations, and specific activities were measured with $\operatorname{HPLC}(16)$, using $\left[{ }^{2} \mathrm{H}_{31}\right]$ palmitate as an internal standard (17). Plasma insulin (18), glucagon (19), and growth hormone concentrations (20) were determined by radioimmunoassay, and plasma epinephrine and norepinephrine were measured by radioenzymatic assay (21). Plasma glucose concentrations were measured with a glucose analyzer (YSI, Yellow Springs, $\mathrm{OH}$ ). Plasma lactate was assayed by methods described previously (22), and $\beta$-hydroxybutyrate and acetoacetate were measured using the methods of Cahill et al. (23).

Methods. Lean body mass (LBM) was measured with body-potassium counting (24) and total body fat by dual energy $x$-ray absorptiometry (DPX; Lunar Radiation Corp. Inc., Madison, WI). Each subject's peak oxygen consumption (peak $\mathrm{VO}_{2}$ ) was measured on two separate occasions with a continuous bicycle-exercise test (Schwinn Air-dyne, Chicago, IL). Exercise was initiated at $150 \mathrm{kpm} \cdot \mathrm{min}^{-1}$ and increased $150 \mathrm{kpm} \cdot \mathrm{min}^{-1}$ every $2 \mathrm{~min}$. until exhaustion. Oxygen uptake and carbon dioxide production rates were measured breath by breath throughout exercise with a CPX Max metabolic cart (Medical Graphics Corp., St. Paul, MN). The highest $\mathrm{VO}_{2}$ attained during either test was considered peak $\dot{\mathrm{VO}}_{2}$. After $16 \mathrm{wk}$ of weight loss, the subjects repeated the maximal aerobic-capacity test only once.

Protocol. Each subject was admitted to the Mayo Clinic General Clinical Research Center the evening before each study, and a standard evening meal was provided at 1800 hours. An 18-gauge forearm intravenous infusion catheter was placed that evening and kept patent with $0.9 \% \mathrm{NaCl}$. At 0700 hours the next morning, a radial artery catheter was placed, under local anesthesia, for blood sampling purposes. Baseline blood samples were obtained to provide background specific activity values for FFA before the infusions. A $\left[1-{ }^{14} \mathrm{C}\right]$ palmitate infusion $\left(\sim 0.3 \mu \mathrm{Ci} \cdot \mathrm{min}^{-1}\right)$ was started more than $30 \mathrm{~min}$ before the first blood sample to allow for isotopic equilibrium. The infusion continued until the end of the study. Basal metabolic rate was established by two 5 min breath samples. Baseline ( $-30-0 \mathrm{~min})$ blood samples were drawn at 10-min intervals between 0730 and 0800 hours for measurement of plasma FFA concentration and specific activity.

Between 0800 and 1030 hours (0-150 min), subjects pedaled continuously on a bicycle ergometer at a workload estimated to be $45 \%$ of peak $\mathrm{VO}_{2}$. Indirect calorimetry measurements were performed at $15-$ min intervals throughout exercise to monitor workload and to calculate carbohydrate and fat oxidation. Workload was also monitored with the digital readout provided with the bicycle ergometer. One obese subject's workload was monitored by digital readout only because of technical problems with the indirect calorimetry measurements. That individual's substrate oxidation data are omitted. Blood samples were taken simultaneously with breath samples during exercise. Between 1030 and 1200 hours ( $150-240 \mathrm{~min}$ ), blood and breath samples were taken at 15-min intervals while the subjects rested quietly in bed. Plasma hormone concentrations were measured at rest and on the last three exercise and recovery blood samples, whereas catecholamine concentrations were measured at most blood-sampling time points.

\section{Weight reduction program}

After the first experiment, all obese subjects participated in a weightloss program. Moderate caloric restriction was employed $(\sim 500$ $\mathrm{kcal} \cdot \mathrm{d}^{-1}$ energy deficit). The recommended energy content of each individual's diet was based on measured resting energy expenditure. The recommended diet composition was $25-30 \%$ fat, $20 \%$ protein, and $50-55 \%$ carbohydrate (80\% complex carbohydrate) and was planned according to subjects' food preferences and tolerances. All subjects were asked to increase their physical activity level but were not required to attend preplanned exercise classes. Half of the subjects of each group were specifically instructed to exercise three times a week for $30 \mathrm{~min}$ at $60-80 \%$ of their maximal heart rate.

Analysis and calculations. Throughout the remainder of the paper, pre- vs. posttesting refers to the testing before and after weight loss, whereas the time points at which samples were taken are referred to as the sampling intervals, e.g., baseline $(-30-0 \mathrm{~min})$, exercise $(0-150$ $\mathrm{min}$ ), and recovery (150-240 $\mathrm{min}$ ). Plasma FFA rate of appearance ( $\mathrm{Ra}$ ) was calculated using non-steady-state equations (25). The rates of fatty acid and carbohydrate oxidation $\left(\mu \mathrm{mol} \cdot \mathrm{min}^{-1}\right)$ were calculated using the indirect calorimetry data combined with urine nitrogen excretion rates (26). At each sampling period, the mean of two 1-min breath samples was used for the calculation of $\dot{\mathrm{VO}}_{2}$ and carbon dioxide production. Baseline FFA flux was the average of three basal Ra values. The total FFA available (isotopic determination) and fatty acids oxidized (indirect calorimetry) during exercise and recovery was calculated using the area under the curve of FFA Ra and fatty acid oxidation, respectively. In order to examine the effect of the exercise stimulus independent of baseline values, the incremental lipolytic response to exercise was calculated by determining the area under the curve above baseline FFA Ra. Free fatty acid availability and fatty acid oxidation are expressed as total $\mu \mathrm{mol}$ or mmol because lean body mass was comparable between groups (27). Statistical comparisons between groups were performed using an ANOVA, and post hoc comparisons were done with the Newman-Keuls test (CLINFO Software Products Corp., Cambridge, MA). Comparisons of plasma FFA kinetics, hormone concentrations, and fatty acid oxidation values between basal, exercise, and recovery time points were made with an ANOVA for repeated measures (Statistical Analysis Software, Cary, NC). Data are expressed as the mean \pm the standard error.

\section{Results}

Descriptive characteristics. The two groups of obese women did not differ with respect to weight, body mass index, or percent body fat (Table I), and the Non Ob women were well matched to the obese women except for body fat. 18 of the 24 obese subjects ( $8 \mathrm{LB} \mathrm{Ob}, 10 \mathrm{UB} \mathrm{Ob}$ ) completed the second study, and their post-weight-loss descriptive and testing data is included in Table I. Because no differences in fatty acid metabolism were present between the women given specific exercise instruction and the group not given specific instructions, the data from the two exercise groups were pooled. Both groups of obese women lost weight at similar rates $\left(\sim 0.5 \mathrm{~kg} \cdot \mathrm{wk}^{-1}\right)$ during the 16-wk weight-reduction program. During the first exercise experiment, all subjects pedaled at a work intensity of approximately $45 \%$ of their individual peak $\mathrm{VO}_{2}$. The obese subjects worked at comparable oxygen uptake rates pre- and post-weight loss ( Table I). 


\begin{tabular}{|c|c|c|c|c|c|}
\hline & \multirow[b]{2}{*}{ Non OB } & \multicolumn{2}{|c|}{ Pre-weight Loss } & \multicolumn{2}{|c|}{ Post-weight Loss } \\
\hline & & LB Ob & $\mathrm{UB} \mathrm{Ob}$ & LB Ob & UB Ob \\
\hline & $n=8$ & $n=11$ & $n=13$ & $n=8$ & $n=10$ \\
\hline Age (yr) & $36 \pm 1$ & $36 \pm 2$ & $36 \pm 2$ & & \\
\hline Weight (kg) & $59.3 \pm 1.9$ & $85.3 \pm 2.1$ & $89.8 \pm 2.0$ & $78.6 \pm 2.6$ & $80.4 \pm 2.7$ \\
\hline Body mass index $\left(\mathrm{kg} \cdot \mathrm{m}^{-2}\right)$ & $22.1 \pm 0.6$ & $31.5 \pm 0.4$ & $33.4 \pm 0.5$ & $29.0 \pm 0.4$ & $30.2 \pm 0.7$ \\
\hline Lean body mass $(\mathrm{kg})$ & $42.0 \pm 0.9$ & $43.9 \pm 1.5$ & $43.5 \pm 0.8$ & $43.9 \pm 1.5$ & $43.9 \pm 1.7$ \\
\hline Percent body fat & $30 \pm 1^{*}$ & $50 \pm 3$ & $48 \pm 2$ & $43 \pm 2^{\ddagger}$ & $43 \pm 1^{\ddagger}$ \\
\hline Waist:hip ratio & $0.72 \pm 0.01$ & $0.73 \pm 0.1$ & $0.89 \pm 0.2$ & $0.77 \pm .01$ & $0.86 \pm .03$ \\
\hline$\dot{\mathrm{VO}}_{2}$ peak $\left(\mathrm{ml} \cdot \mathrm{kg} \mathrm{LBM}{ }^{-1} \cdot \min ^{-1}\right)$ & $40.1 \pm 2.0$ & $42.9 \pm 1.5$ & $38.4 \pm 1.5$ & $47.6 \pm 1.2^{\ddagger}$ & $43.7 \pm 2.1^{\ddagger}$ \\
\hline Baseline $\dot{\mathrm{VO}}_{2}(\mathrm{ml} / \mathrm{min})$ & $180 \pm 9$ & $189 \pm 6$ & $206 \pm 7$ & $198 \pm 11$ & $216 \pm 8$ \\
\hline Exercise $\dot{\mathrm{V}}_{2}(\mathrm{ml} / \mathrm{min})$ & $750 \pm 39$ & $886 \pm 20$ & $827 \pm 40$ & $847 \pm 21$ & $798 \pm 25$ \\
\hline Recovery $\dot{\mathrm{VO}}_{2}(\mathrm{ml} / \mathrm{min})$ & $193 \pm 10$ & $224 \pm 12$ & $248 \pm 12$ & $224 \pm 16$ & $242 \pm 7$ \\
\hline
\end{tabular}

Non $\mathrm{Ob}$, nonobese; LB Ob, lower body obese; UB Ob, upper body obese. ${ }^{*} P<0.01$ cf. other groups; ${ }^{\ddagger} P \leqslant 0.05$ cf. pre-weight loss.

Plasma hormone, glucose, and substrate concentrations. Plasma insulin concentrations before, during, and after exercise are provided in Table II. The pattern of differences is similar to that previously reported (1), and during exercise plasma insulin concentrations decreased. Baseline, exercise, and recovery plasma insulin concentrations were modestly lower during the post-weight-loss study than during the pre-weight-loss study in both groups of obese women (Table II).

The three groups of women had similar baseline plasma cortisol and glucagon concentrations, which increased $(P$ $<0.05) \sim 20 \%$ in response to exercise and returned to baseline values during recovery (data not shown). No significant difference in plasma growth hormone concentrations was found between groups or between sampling intervals, and no substantial differences between pre- and post-weight-loss plasma cortisol, growth hormone, and glucagon concentrations were apparent in $\mathrm{UB} \mathrm{Ob}$ or $\mathrm{LB} \mathrm{Ob}$ women (data not shown).

Plasma norepinephrine and epinephrine concentrations increased $(P<0.05)$ in response to exercise in all groups (Fig. 1). During exercise the plasma norepinephrine concentrations increased abruptly and remained stable, whereas plasma epinephrine concentrations increased gradually throughout exercise.
Although plasma catecholamine concentrations tended to be lower during the post-weight-loss exercise study, no statistically significant differences in plasma catecholamines between groups was found either pre- or post-weight loss.

Plasma glucose concentrations were similar between groups at baseline and did not change significantly throughout exercise or recovery (baseline: Non $\mathrm{Ob} 5.2 \pm 0.1$, LB Ob $5.4 \pm 0.1$, UB Ob $\left.5.8 \pm 0.2 \mathrm{mmol} \cdot \mathrm{L}^{-1}\right)$. Baseline plasma lactate concentrations were greater $(P<0.05)$ in UB Ob $(1.6 \pm 0.1$ $\mathrm{mmol} /$ liter $)$ than Non $\mathrm{Ob}(1.0 \pm 0.1 \mathrm{mmol} /$ liter $)$ and LB Ob $(1.2 \pm 0.1 \mathrm{mmol} /$ liter $)$ women. In all subjects, plasma lactate concentrations increased $(P<0.05) \sim 0.5 \mathrm{mmol} /$ liter during exercise and returned to baseline values during recovery. Plasma ketone body concentrations increased during exercise in each group and continued to increase during recovery ( $\mathrm{Ta}$ ble II). No statistically significant differences in plasma glucose, lactate, or ketone body concentrations were seen from pre- to post-weight loss in UB Ob or LB Ob women.

\section{Fatty acid kinetics}

Baseline. Baseline FFA flux was greater $(P<0.05)$ in UB Ob women than either Non $\mathrm{Ob}$ or $\mathrm{LB} \mathrm{Ob}$ women $(517 \pm 43$ vs.

Table II. Plasma Insulin and Ketone Body Concentrations

\begin{tabular}{|c|c|c|c|c|c|}
\hline & \multirow[b]{2}{*}{ Non $\mathrm{Ob}$} & \multicolumn{2}{|c|}{ LB Ob } & \multicolumn{2}{|c|}{$\mathrm{UB} \mathrm{Ob}$} \\
\hline & & Pre & Post & Pre & Post \\
\hline & $n=8$ & $n=11$ & $n=8$ & $n=13$ & $n=10$ \\
\hline \multicolumn{6}{|c|}{ Insulin $\left(\mathrm{pmol} ; \cdot\right.$ liter $\left.^{-1}\right)$} \\
\hline Baseline & $39 \pm 4^{\ddagger}$ & $68 \pm 6^{*}$ & $62 \pm 8^{*}$ & $109 \pm 13$ & $99 \pm 16^{*}$ \\
\hline Exercise & $30 \pm 6^{\ddagger}$ & $44 \pm 5^{\ddagger}$ & $30 \pm 4^{\ddagger \S}$ & $77 \pm 8^{\prime \prime}$ & $64 \pm 10$ \\
\hline Recovery & $21 \pm 2^{\ddagger \|}$ & $41 \pm 6$ & $30 \pm 5^{\ddagger}$ & $88 \pm 14$ & $51 \pm 5^{\S}$ \\
\hline \multicolumn{6}{|c|}{ Ketone bodies $\left(\mu \mathrm{mol} \cdot\right.$ liter $\left.^{-1}\right)$} \\
\hline Baseline & $388 \pm 141^{*}$ & $64 \pm 37^{*}$ & $199 \pm 70^{*}$ & $127 \pm 23^{*}$ & $189 \pm 76^{*}$ \\
\hline Exercise & $736 \pm 125$ & $539 \pm 105$ & $369 \pm 91$ & $351 \pm 87$ & $378 \pm 78$ \\
\hline Recovery & $1537 \pm 181^{\ddagger}$ & $1258 \pm 120$ & $990 \pm 172$ & $956 \pm 156$ & $1011 \pm 198$ \\
\hline
\end{tabular}

Pre- and Post- refer to studies performed before and after $16 \mathrm{wk}$ of an energy-restricted diet resulting in weight loss (see text). ${ }^{*} P<0.01 \mathrm{cf}$. exercise and recovery; ${ }^{\ddagger} P<0.05 \mathrm{cf}$. UB Ob; ${ }^{\S} P<0.05 \mathrm{cf}$. Pre; " $P<0.01 \mathrm{cf}$. baseline. 


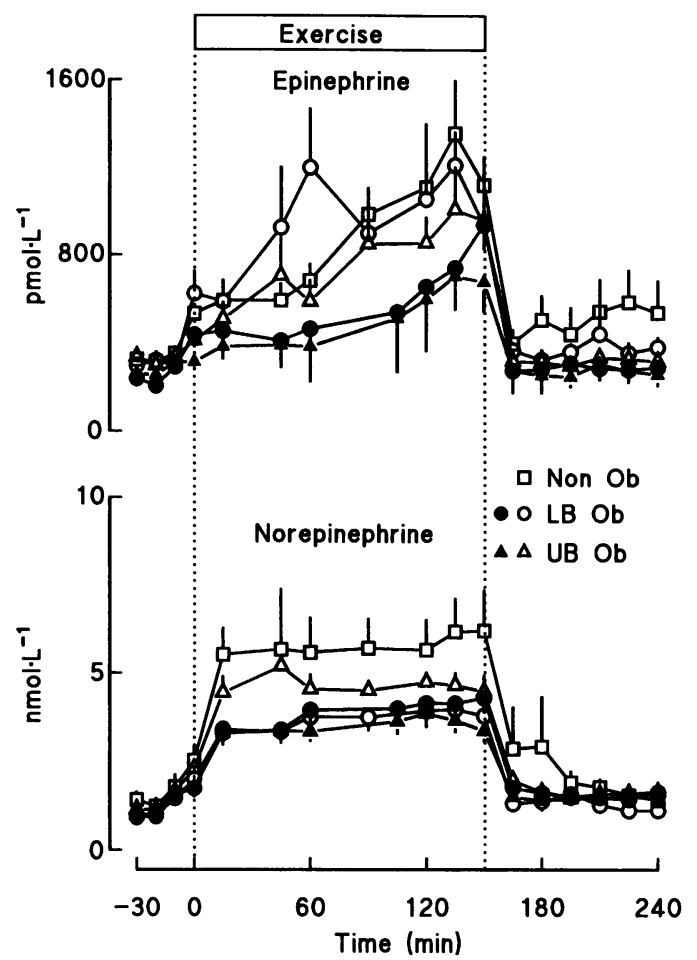

Figure 1. Baseline (-30-0), exercise (0-150), and recovery (150240) plasma epinephrine and norepinephrine concentrations. Open symbols represent pre-weight loss values; closed symbols represent post-weight loss values.

$384 \pm 38$ vs. $398 \pm 53 \mu \mathrm{mol} \cdot \mathrm{min}^{-1}$, respectively). Baseline fatty acid oxidation, by indirect calorimetry, was UB Ob $268 \pm 36$, Non $\mathrm{Ob} 160 \pm 27$, and $\mathrm{LB} \mathrm{Ob} 210 \pm 27 \mu \mathrm{mol} \cdot \min ^{-1}(P=\mathrm{NS}$ between groups). Free fatty acid flux exceeded $(P<0.05)$ fatty acid oxidation in each group. After 16 wk of the energyrestricted diet, basal FFA flux increased $(P=\mathrm{NS})$ slightly in the $\mathrm{LB} \mathrm{Ob}$ women such that the mean values were now very similar to those of UB Ob women $(542 \pm 59$ vs. $555 \pm 74$ $\mu \mathrm{mol} \cdot \mathrm{min}^{-1}$, respectively, $\left.P=\mathrm{NS}\right)$. The post-weight-loss baseline fatty acid oxidation rates in $\mathrm{LB} \mathrm{Ob}$ and $\mathrm{UB} \mathrm{Ob}$ women were $260 \pm 18$ and $215 \pm 33 \mu \mathrm{mol} \cdot \mathrm{min}^{-1}$, respectively $(P=\mathrm{NS}$, $\mathrm{LB} \mathrm{Ob}$ vs. UB $\mathrm{Ob}$ and pre- vs. post-).

Exercise. Figs. 2 and 3 depict the responses of plasma FFA $\mathrm{Ra}$ and fatty acid oxidation rates throughout the first experiment between groups and within groups. Although the pattern of change in plasma FFA Ra is not different between the three groups (Fig. 3), UB Ob women started with the highest preexercise FFA flux (Fig. 3) and had the lowest mean peak exercise FFA Ra values. Therefore, over the $150 \mathrm{~min}$ of exercise the increment in FFA availability above baseline in Non $\mathrm{Ob}$ and LB Ob women $(51 \pm 7$ and $53 \pm 8 \mathrm{mmol}$, respectively) was greater than that found in UB Ob women $(27 \pm 4 \mathrm{mmol}, P$ $<0.05$ ).

During the initial exercise study, FFA Ra and fatty acid oxidation rates matched closely in $\mathrm{UB} \mathrm{Ob}$ and $\mathrm{Non} \mathrm{Ob}$ women (Fig. 2), whereas in LB Ob women FFA Ra tended to increase more slowly than fatty acid oxidation during the first $60 \mathrm{~min}$ of exercise. During the $150 \mathrm{~min}$ of exercise the total FFA available (area under the FFA Ra curve) in Non Ob, LB Ob, and UB Ob women $(107 \pm 8,112 \pm 13$, and $100 \pm 6 \mathrm{mmol}$, respectively $)$ and the total amount of fatty acids oxidized $(86 \pm 13,103 \pm 29$, and

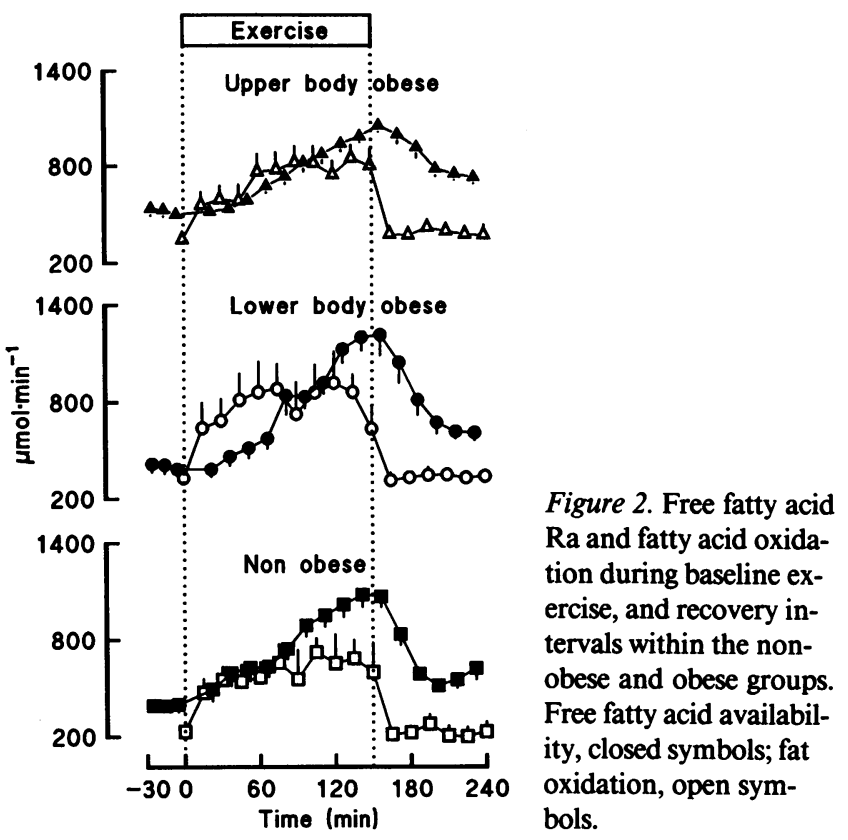

$98 \pm 12 \mathrm{mmol}$, respectively) were not significantly different either between groups or Ra vs. oxidation (Fig. 4). The mean FFA Ra during the last $30 \mathrm{~min}$ of exercise was $1042 \pm 52$, $996 \pm 82,989 \pm 90$, and $\mu \mathrm{mol} \cdot \mathrm{min}^{-1}$ in the Non Ob, LB Ob, and $\mathrm{UB} O \mathrm{Ob}$ women, respectively, and fatty acid oxidation rates over the same time interval were $660 \pm 144,806 \pm 127$, and $797 \pm 92$ $\mu \mathrm{mol} \cdot \min ^{-1}$.

After weight loss, the plasma FFA Ra response to exercise increased in both LB Ob and UB Ob women (Fig. 5), although plasma FFA concentrations were virtually identical pre- and post-weight loss (data not shown). The increment in FFA availability above baseline during the $150 \mathrm{~min}$ of exercise was

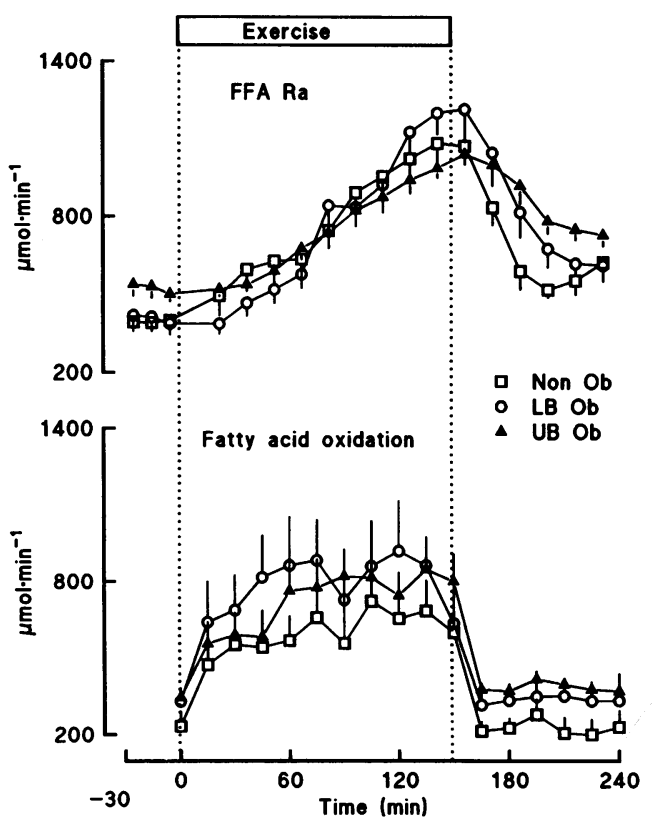

Figure 3. Free fatty acid rate of appearance ( $\mathrm{Ra}$ ) and fatty acid oxidation rates during baseline exercise, and recovery intervals between groups. 


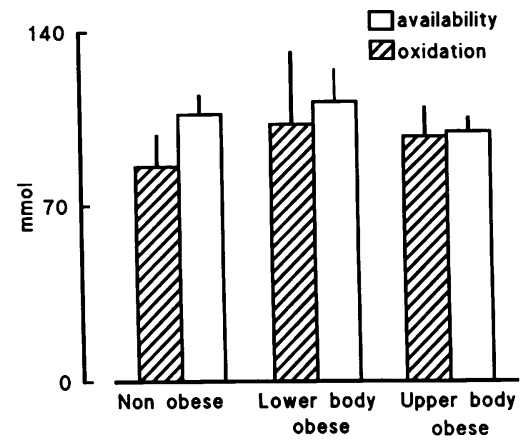

Figure 4. Free fatty acid availability (isotope determination) and fat oxidation (indirect calorimetry) summed throughout the $150 \mathrm{~min}$ of exercise. greater in $\mathrm{LB}$ Ob women than $\mathrm{UB}$ Ob women ( $91 \pm 11$ vs. $53 \pm 8$ mmol, respectively, $P<0.005)$. In addition, total FFA availability during exercise was greater following weight loss $(P$ $<0.05$ ) in both LB Ob and UB Ob women (LB Ob, pre- vs. post-: $115 \pm 16$ vs. $173 \pm 17 \mathrm{mmol}$; UB Ob, pre- vs. post-: $104 \pm 7$ vs. $143 \pm 10 \mathrm{mmol}$, respectively) (Fig. 6). Despite the markedly increased FFA availability, fatty acid oxidation during the $2.5 \mathrm{~h}$ of exercise was not statistically different from pre-weight-loss values in either groups (LB Ob, pre- vs. post-: $94 \pm 31$ vs. $109 \pm 11$, UB Ob, pre- vs. post-: $119 \pm 21$ vs. $78 \pm 13 \mathrm{mmol}$ ) (Fig. 6).

Recovery. Oxygen consumption returned to baseline values within the first $15 \mathrm{~min}$ of the 90 -min recovery interval in all groups. Free fatty acid availability clearly exceeded fatty acid oxidation in all groups (FFA availability vs. fat oxidation: Non $\mathrm{OB}, 118 \pm 21$ vs. $34 \pm 5$, LB Ob; $146 \pm 8$ vs. $53 \pm 6$; $\mathrm{UB} \mathrm{Ob}$, $162 \pm 15$ vs. $59 \pm 5 \mathrm{mmol}$, respectively; $P<0.01$ ) (Fig. 3); no statistically significant intergroup differences were present. Following weight loss, recovery interval FFA availability also exceeded recovery interval fatty acid oxidation (LB Ob, 198 \pm 15 vs. $45 \pm 6$; UB Ob, $160 \pm 15$ vs. $42 \pm 6 \mathrm{mmol} ; P<0.01$, respectively).

Carbohydrate oxidation. As measured by indirect calorimetry, baseline carbohydrate oxidation was $638 \pm 267,596 \pm 134$, and $578 \pm 113 \mu \mathrm{mol} \cdot \mathrm{min}^{-1}(P=\mathrm{NS})$ in Non Ob, LB Ob, and $\mathrm{UB} O \mathrm{Ob}$ women, respectively. The quantity of carbohydrate oxidized during exercise was also similar $(422 \pm 45$ vs. $450 \pm 53$ vs. $522 \pm 73 \mathrm{mmol}$, respectively, $P=\mathrm{NS}$ ). Although fat oxidation

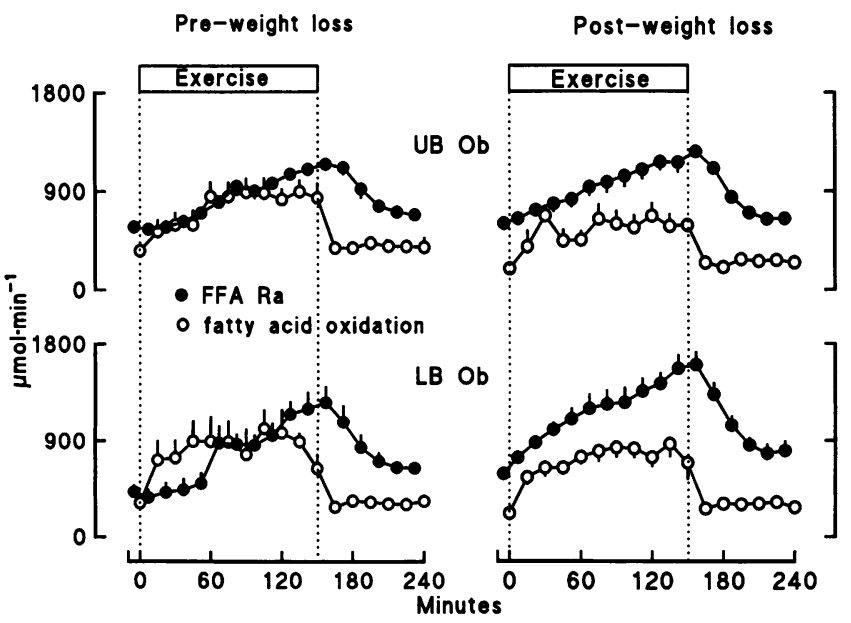

Figure 5. Free fatty acid $\mathrm{Ra}$ and fatty acid oxidation rates during baseline exercise, and recovery intervals, pre- and post-weight loss in upper-body obese (UB Ob) and lower-body obese ( $\mathrm{LB} \mathrm{Ob}$ ) women.

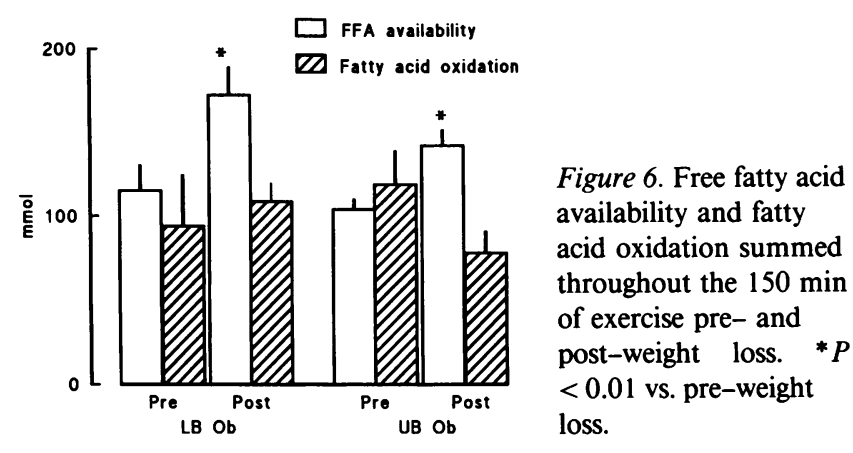

increased gradually throughout exercise in all groups, at no time did fat oxidation exceed carbohydrate oxidation. Protein oxidation was a negligible energy source. No differences in carbohydrate oxidation during the $90 \mathrm{~min}$ of recovery were seen between groups. During exercise the quantities of carbohydrate oxidized were not significantly different pre- or post-weight loss (LB Ob, $461 \pm 94$ vs. $355 \pm 35 \mathrm{mmol}$; UB Ob, $452 \pm 62$ vs. $385 \pm 30 \mathrm{mmol}$; respectively, $P=\mathrm{NS}$ ). Carbohydrate oxidation contributed slightly more than $50 \%$ of the calories utilized during exercise before weight loss and slightly less than $50 \%$ of the calories following weight loss.

\section{Discussion}

These experiments were performed to address a void in the literature regarding lipid fuel metabolism during exercise in women. The influence of obesity, body-fat distribution, and an energy-restricted diet on FFA availability and fatty acid oxidation during exercise was assessed. We measured FFA turnover and fatty acid oxidation rates in age- and fitness-matched upper body obese, lower body obese, and nonobese women before, during, and after prolonged, submaximal bicycle exercise, before and during weight loss (obese women only). Because previous studies (1) found a reduced FFA response to intravenous epinephrine in upper body obesity, we hypothesized that women with this obesity phenotype would have a reduced net FFA response to exercise, and that a weight-loss program would exaggerate this difference. Consistent with the epinephrine infusion data (1), upper body obese women in this study had a reduced incremental FFA response to exercise. Despite this subnormal response, total FFA availability and fatty acid oxidation was not different between upper body obese, lowerbody obese, or nonobese women. After 16 wk of an energyrestricted diet, baseline FFA flux was no longer different in UB $\mathrm{Ob}$ and $\mathrm{LB} \mathrm{Ob}$ women, the FFA response to exercise increased in both groups of obese women, yet $\mathrm{UB} \mathrm{Ob}$ women continued to have a lesser net lipolytic response than $\mathrm{LB} \mathrm{Ob}$ women. Thus, the reduced net FFA response in upper-body obese women could not be interpreted as a normal increase from a higher preexercise FFA level in order to meet the oxidative demands of exercise but must be related to differences in adipose tissue or the hormonal milieu of exercise in upper body obesity.

We employed two approaches to assess the FFA kinetic response to exercise. The total FFA available (area under the curve of FFA Ra) is a measure of the total circulating lipid fuel present during the $150 \mathrm{~min}$ of exercise. From an energy supply and demand perspective, upper body obese women responded appropriately to the exercise. It must be acknowledged, how- 
ever, that if FFA availability is a limiting factor for fatty acid oxidation during exercise, the comparison between availability and oxidation may be falsely reassuring. The second method of analysis was to compare the incremental FFA response to the exercise stimulus. This choice of data analysis is independent of baseline values and may therefore provide an index of how lipolytically responsive adipose tissue is to the effects of exercise. From this perspective, it was evident that upper body obese women had a lesser FFA response than nonobese and lower body obese women despite similar increases in catecholamines and decreases in insulin. The finding that $\mathrm{UB} \mathrm{Ob}$ women continued to have a lesser FFA response to exercise than LB Ob women following weight loss suggests that this difference is not merely an anomaly of the choice of data presentation.

There is abundant data concerning the FFA kinetic response to exercise in men $(3,6,7,10,28,29)$ however, we are aware of only one study in women (30). FFA turnover increased by $19 \%$ and $64 \%$ in two obese women (no nonobese controls were included) during $30 \mathrm{~min}$ of bicycle ergometer exercise (30). More comprehensive information is important in light of the known differences in the metabolic responses to exercise between men and women (11). Our findings in nonobese women are similar to those of Wolfe et al. (10), who noted that FFA availability exceeded fatty acid oxidation throughout exercise in lean men, and this is consistent with the calculations of Gollnick (9) who estimated substrate flow through a muscle during exercise exceeded metabolic requirements. The greater FFA availability than fatty acid oxidation suggests that plasma FFA from hydrolysis of adipose tissue triglycerides can potentially meet the oxidative needs of working muscle during moderate-level exercise. Theoretically, net depletion of intramuscular fat should not be a problem or limit low intensity exercise capacity in lean men or women. The pattern of FFA availability in the lower body obese women during the first hour of exercise (Fig. 2) suggests that the potential for depletion of intramuscular triglyceride fatty acids during brief exercise exists in this obesity phenotype.

It must be acknowledged that our estimates of FFA availability and fatty acid oxidation in this study are only approximations. Although the isotope dilution technique appears to be quantitatively accurate in measuring systemic plasma FFA Ra $(16,17,25)$, it may underestimate total FFA Ra. Some FFA released from visceral adipose tissue are removed by the liver before complete mixing with the FFA tracer (31), thus total body FFA Ra would be greater than tracer estimates. However, this underestimate is relatively small at rest (32) and likely an even smaller proportion of total FFA Ra during exercise (33). In addition, it is possible to err in the estimation of fatty acid oxidation during exercise ( 34 ) and recovery because of changes in plasma ketone body and lactate concentrations (26). Plasma ketone body concentrations increased in our subjects throughout the study with the greatest increase seen during the 90-min recovery interval in the nonobese women (Table II). The net accumulation of ketone bodies in this group could result in $\mathrm{O}_{2}$ consumption of $\sim 3 \mathrm{ml} \cdot \mathrm{min}^{-1}(\sim 1.5 \%$ of total $\mathrm{O}_{2}$ consumption ) without $\mathrm{CO}_{2}$ production, resulting in a lower $R Q$ value. In addition, plasma lactate concentrations decreased by $\sim 0.5 \mathrm{mmol} \cdot$ liter $^{-1}$ during recovery, potentially resulting in the retention of an additional $1.6 \mathrm{ml} \cdot \mathrm{min}^{-1}$ of $\mathrm{CO}_{2}$. These confounding factors could theoretically result in a $2.5 \%$ underestimate of RQ ( an error within the measurement error of indi- rect calorimetry). The obese groups had smaller changes in plasma substrate concentrations, and the effects would be relatively less important during exercise. Thus, we believe our indirect calorimetry estimates of fatty acid oxidation are reasonably accurate; however, this may not necessarily be true at higher workloads (34).

These study results suggest that increased FFA availability during exercise does not necessarily result in increased fatty acid oxidation, unlike the responses following exercise training or fasting. Endurance-training studies show increased fatty acid oxidation during exercise without intramuscular glycogen depletion $(35,36)$; whereas, glycogen depletion is believed to be responsible for the increased exercise fatty acid oxidation following fasting (14). In the present study, the subjects were neither well trained nor glycogen depleted before or during weight loss. Thus, the failure of increased FFA availability to increase fatty acid oxidation suggests that factors other than circulating FFA regulate fatty acid oxidation during exercise.

The mechanism(s) for the increased FFA response to exercise following weight loss and the smaller incremental lipolytic responses seen in upper body obese women cannot be established from this study. Insulin (37) and catecholamines $(2,4)$ are the major regulators of adipose tissue lipolysis, and changes may have occurred in both regulatory systems with weight loss, which may enhance the lipolytic response to exercise. For example, plasma insulin concentrations were slightly lower in both groups throughout the post-weight-loss study, which could allow a greater lipolytic response. However, the relative decrease in insulin during exercise was comparable pre- and post-weight loss, arguing against insulin being solely responsible for the greater FFA release. Although the plasma epinephrine and norepinephrine concentrations during exercise were comparable before and after weight loss, in vitro (38) and in vivo (15) studies have shown that food restriction increases the stimulatory effects of catecholamines on lipolysis, even if insulin availability is controlled (15). Thus, an enhanced adipose tissue response to catecholamines may play a substantial role in the increased FFA availability seen in the post-weight loss exercise study. Although the greater plasma insulin concentrations present in upper body obese women may have contributed to the reduced lipolytic response to exercise compared with lower body obese women, the differences in catecholamine regulation of adipose tissue lipolysis between these two types of obesity $(1,39)$ more likely account for the lesser response in upper body obese women.

The markedly different FFA response to exercise following a relatively gradual loss of weight has implications for the recruitment of volunteers for research studies. The subjects in this experiment were weight stable for at least two months (and often years) prior to initial involvement in this study; whereas, in the second study weight loss was continuing to occur. It is possible that the ongoing caloric deficits, rather than fat loss itself, in some way mediated the responses observed. It is unknown how long an enhanced FFA response to exercise would persist following weight stabilization. In future studies it will be important to determine whether study subjects have lost weight and, if so, how long a stable weight has been maintained. Failure to take such a precaution could result in different metabolic responses to exercise.

In summary, we have found that healthy, premenopausal, upper body obese women have a reduced net lipolytic response to submaximal exercise compared with lower body obese and 
nonobese women. Despite this difference, upper body obesity is not associated with inadequate fuel mobilization relative to energy needs during exercise, either before or during a weightreduction program. Thus, lack of participation in physical activities cannot be attributed to defects in energy availability. The different exercise FFA Ra response confirms that the adipose response to physiologic, lipolytic stimuli varies between upper body and lower body obesity.

\section{Acknowledgments}

We would like to thank the staff of the Mayo Clinic General Clinical Research Center and the St. Mary's Respiratory Therapy department for their assistance in the conduct of these studies, and Carol Demulling for editorial assistance.

Dr. Kanaley was selected as an Ethan Sims Young Investigator finalist at the 1991 meeting of North American Society of the Study of Obesity. Dr. Kanaley was funded by National Institutes of Health training grant DK1-107352. This study was supported by grants DK1140484, RR-00035, RR-00585, DK1-127085, and RR-00036 from the U. S. Public Health Service and by the Mayo Foundation.

\section{References}

1. Jensen, M. D., M. W. Haymond, R. A. Rizza, P. E. Cryer, and J. M. Miles 1989. Influence of body fat distribution on free fatty acid metabolism in obesity. J. Clin. Invest. 83:1168-1173.

2. Galster, A. D., W. E. Clutter, P. E. Cryer, J. A. Collins, and D. M. Bier. 1981. Epinephrine plasma thresholds for lipolytic effects in man. Measurements of fatty acid Transport with $\left[1-{ }^{13} \mathrm{C}\right]$ palmitic acid. J. Clin. Invest. 67:1729-1738.

3. Wahrenberg, H., P. Engfeldt, J. Bolinder, and P. Arner. 1987. Acute adaptation in adrenergic control of lipolysis during physical exercise in humans. Am. J. Physiol. 253 (Endocrinol. Metab. 16):E383-E390.

4. Marker, J. C., I. B. Hirsch, L. J. Smith, C. A. Parvin, J. O. Holloszy, and P. E. Cryer. 1991. Catecholamines in prevention of hypoglycemia during exercise in humans. Am. J. Physiol. 260 (Endocrinol. Metab. 23):E705-E712.

5. Wood, P. D., M. L. Stefanick, P. T. Williams, and W. L. Haskell. 1991. The effects of plasma lipoproteins of a prudent weight-reducing diet, with or without exercise, in overweight men and women. $N$. Engl. J. Med. 325:461-466.

6. Havel, R. J., A. Naimark, and C. F. Borchgrevink. 1963. Turnover rate and oxidation of free fatty acids of blood plasma in man during exercise: studies during continuous infusion of palmitate-1-C ${ }^{14}$. J. Clin. Invest. 42:1054-1063.

7. Ahlborg, G., P. Felig, L. Hagenfeldt, R. Hendler, and J. Wahren. 1974. Substrate turnover during prolonged exercise in man. J. Clin. Invest. 53:10801090.

8. Holloszy, J., 1990. Utilization of fatty acids during exercise. In Biochemistry of Exercise. A. W. Taylor, P. D. Gollnick, H. J. Green, E. G. Lanuzzo, E. G. Noble, G. Mítivier, and J. R. Sutton, editors. Human Kinetics, Champaign, IL. 319-327.

9. Gollnick, P. D. 1977. Free fatty acid turnover and the availability of substrates as a limiting factor in prolonged exercise. Ann. N. Y. Acad. Sci. 301:65-71.

10. Wolfe, R. R., S. Klein, F. Carraro, and J.-M. Weber. 1990. Role of triglyceride-fatty acid cycle in controlling fat metabolism in humans during and after exercise. Am. J. Physiol. 258:E382-E389.

11. Tarnopolsky, L. J., J. D. MacDougall, S. A. Atkinson, M. A. Tarnopolsky, and J. R. Sutton. 1990. Gender differences in substrate for endurance exercise. $J$. Appl. Physiol. 68:302-308.

12. Issekutz, B., W. M. Bortz, H. I. Miller, and A. Wroldsen. 1967. Plasma free fatty acid response to exercise in obese humans. Metab. Clin. Exp. 16:492-502.

13. Minuk, H. L., A. K. Hanna, E. B. Marliss, M. Vranic, and B. Zinman. 1980. Metabolic response to moderate exercise in obese man during prolonged fasting. Am. J. Physiol. 238 (Endocrinol. Metab. I):E322-E329.

14. Scheen, A., A. Cession-Fossion, M. Scheen-Lavigne, and A. Luyckx. 1982. Effect of protein-supplemented fasting on metabolic and hormonal re- sponses to epinephrine infusion in obese subjects. Horm. Metab. Res. 14:240245.

15. Jensen, M. D., M. W. Haymond, J. E. Gerich, P. E. Cryer, and J. M. Miles. 1987. Lipolysis during fasting: decreased suppression by insulin and increased stimulation by epinephrine. J. Clin. Invest. 79:207-213.

16. Miles, J. M., M. G. Ellman, K. L. McClean, and M. D. Jensen. 1987. Validation of a new method for determination of free fatty acid turnover. Am. J. Physiol. 252:E431-E438.

17. Jensen, M. D., P. J. Rogers, M. G. Ellman, and J. M. Miles. 1988. Choice of infusion-sampling mode for tracer studies of free fatty acid metabolism. Am. J. Physiol. 254 (Endocrinol. Metab. 17):E562-E565.

18. Herbert, V., K. S. Lav, G. W. Gottlieb, and S. J. Bleicher. 1965. Coatedcharcoal immunoassay of insulin. J. Clin. Endocrinol. \& Metab. 25:1375-1384.

19. Faloona, G., and R. H. Unger. 1974. Glucagon. In Methods of Hormone Radioimmunoassay. B. Jaffe and H. Behrman, editors. Academic Press, Inc., San Diego, CA. 317-330.

20. Peake, G. T. 1974. Growth Hormone. In Methods of Hormone Radioimmunoassay. B. Jaffe and H. R. Behrman, editors. Academic Press, Inc., San Diego, CA. 103-121.

21. Shah, S. D., W. E. Clutter, and P. E. Cryer. 1985. External and internal standards in the single isotope derivative (radioenzymatic) assay of plasma norepinephrine and epinephrine in normal humans and persons with diabetes mellitus or chronic renal failure. J. Lab. Clin. Med. 106:624-629.

22. Lowry, O. H., and J. V. Passonneau. 1972. A Flexible System of Enzymatic Analysis. Academic Press, Inc., San Diego, CA. 148-212.

23. Cahill, G. F., M. G. Herrera, A. P. Morgan, J. S. Soeldner, J. Steinke, P. L. Levy, G. A. Reichard, Jr., and D. M. Kipnis. 1966. Hormone-fuel interrelationships during fasting. J. Clin. Invest. 45:1751-1769.

24. Jensen, M. D., J. S. Braun, R. J. Vetter, and H. M. Marsh. 1988. Measurement of body potassium with a whole-body counter: relationship between lean body mass and resting energy expenditure. Mayo Clin. Proc. 63:864-888.

25. Jensen, M. D., V. Heiling, and J. M. Miles. 1990. Measurement of nonsteady-state free fatty acid turnover. Am. J. Physiol. 258 (Endocrinol. Metab. 21):E103-E108.

26. Frayn, K. N. 1983. Calculation of substrate oxidation rates in vivo from gaseous exchange. J. Appl. Physiol. 55:628-634.

27. Tanner, J. M. 1949. Fallacy of per weight and per surface area standards and their relation to spurious correlation. J. Appl. Physiol. 2:1-15.

28. Havel, R. J., L. A. Carlson, L. Ekelund, and A. Holmgren. 1964. Turnover rate and oxidation of different free fatty acids in man during exercise. J. Appl. Physiol. 19:613-618.

29. Havel, R. J., L.-G. Ekelund, and A. Holmgren. 1967. Kinetic analysis of the oxidation of palmitate- $1-{ }^{14} \mathrm{C}$ in man during prolonged heavy muscular exercise. J. Lipid Res. 8:366-373.

30. Björntorp, P., H. Bergman, and E. Varnauskas. 1969. Plasma free fatty acid turnover rate in obesity. Acta Med. Scand. 185:351-356.

31. Basso, L. V., and R. J. Havel. 1970. Hepatic metabolism of free fatty acids in normal and diabetic dogs. J. Clin. Invest. 49:537-547.

32. Martin, M. L., and M. D. Jensen. 1991. Effects of body fat distribution on regional lipolysis in obesity. J. Clin. Invest. 88:609-613.

33. Wahren, J., Y. Sato, J. Östman, L. Hagenfeldt, and P. Felig. 1984. Turnover and splanchnic metabolism of free fatty acids and ketones in insulin-dependent diabetics at rest and in response to exercise. J. Clin. Invest. 73:1367-1376.

34. Jones, N. L., G. J. F. Heigenhauser, A. Kuksis, C. G. Matsos, J. R. Sutton, and C. J. Toews. 1980. Fat metabolism in heavy exercise. Clin. Sci. (Lond.). 59:469-478.

35. Holloszy, J. O., and E. F. Coyle. 1984. Adaptations of skeletal muscle to endurance exercise and their metabolic consequences. J. Appl. Physiol. 56:831838.

36. Koivisto, V., R. Hendler, E. Nadel, and P. Felig. 1982. Influence of physical training on the fuel-hormone response to prolonged low intensity exercise. Metab. Clin. Exp. 31:192-197.

37. Hirsch, I. B., J. C. Marker, L. J. Smith, R. J. Spina, C. A. Parvin, J. O. Holloszy, and P. E. Cryer. 1991. Insulin and glucagon in prevention of hypoglycemia during exercise in humans. Am. J. Physiol. 260 (Endocrinol. Metab. 23):E695-E704.

38. Bukowieski, L., J. Lupien, N. Follea, A. Paradis, D. Richard, and J. LeBlanc. 1980. Mechanism of enhanced lipolysis in adipose tissue of exercisetrained rats. Am. J. Physiol. 239 (Endocrinol. Metab. 2):E422-E429.

39. Kissebah, A. H., N. Vydelinqum, R. Murray, D. Evans, A. J. Hartz, R. K. Kalkhoff, and P. W. Adams. 1982. Relation of body fat distribution to metabolic complications of obesity. J. Clin. Endocrinol. \& Metab. 54:254-260. 